\title{
PREPARASI KATALIS ZEOLIT ALAM ASAM SEBAGAI KATALIS DALAM PROSES PIROLISIS KATALITIK POLIETILENA
}

\author{
Tri Windarti, Ahmad Suseno \\ Laboratorium Kimia Fisik Jurusan Kimia \\ Fakultas MIPA Universitas Diponegoro \\ Jl. Prof. Soedarto, SH Tembalang Semarang 50275
}

\begin{abstract}
ABSTRAK
Telah dilakukan penelitian tentang preparasi katalis zeolit alam asam sebagai katalis dalam proses pirolisis katalitik polietilena. Katalis zeolit alam asam dibuat melalui aktivasi dan kalsinasi zeolit alam Wonosari yang meliputi perendaman dalam larutan $\mathrm{HF} 1 \%$, perlakuan $\mathrm{HCl}$, perendaman dalam larutan $\mathrm{NH}_{4} \mathrm{Cl}$ dan kalsinasi dengan dan tanpa gas $\mathrm{N}_{2}$. Proses kalsinasi dilakukan pada temperatur 500 ${ }^{\circ} \mathrm{C}$. Karakter katalis yang meliputi rasio Si/Al, keasaman, luas permukaan, volume pori dan rerata jejari pori, masing-masing ditentukan dengan Spektroskopi Serapan Atom (AAS), metode adsorpsi $\mathrm{NH}_{3}$ dan alat penganalisis luas permukaan. Hasilnya adalah preparasi telah meningkatkan keasaman zeolit sebesar $132,5 \%$, rasio Si/Al sebesar 146,9\%, luas permukaan sebesar $748 \%$, volume pori sebesar $98 \%$ dan menurunkan rerata jejari pori sebesar $76 \%$. Proses pirolisis dan proses pirolisis katalitik dilakukan dengan reactor bach dan produk cair dianalisis dengan GC dan GC-MS serta FTIR. Produk proses pirolisis polietilena adalah olefin $C_{9}-C_{15}$ sedangkan produk pirolisis dengan katalis zeolit alam asam adalah olefin $C_{5}-C_{12}$.
\end{abstract}

Kata kunci: katalis zeolit alam asam, pirolisis, dan pirolisis katalitik

\section{PREPARATION OF ACIDIC NATURAL ZEOLITE CATALYST AS A CATALYST IN CATALYTIC PYROLISIS PROCESS OF POLYETILENE}

\begin{abstract}
Study of the preparation of acidic natural zeolite catalyst as a catalyst in catalytic process of polyetilene has been conducted. The acidic natural zeolite catalyst was prepared by: activation and calcination of natural zeolite from Wonosari. The activation of the zeolite was carried out by HF $(1 \%)$ and $\mathrm{HCl}$ treatment, followed by immersing in the $\mathrm{NH}_{4} \mathrm{Cl}$ solution and calcination with and without $\mathrm{N}_{2}$ gas. The calcination process were conducted at $500{ }^{\circ} \mathrm{C}$. The catalysts characters included Si/Al ratio, acidity, surface area, pore volume and average pore were analyzed by Atomic Adsorption Spectroscopy $(A A S), \mathrm{NH}_{3}$ adsorption method and Surface Area Analyzer, respectively. The results showed that the preparation process has been increased the zeolite acidity of 132.5\%, Si/Al ratio of 146.9\%, surface area of $748 \%$, pore volume of $98 \%$ and has been decreased the average pore of $76 \%$. Pyrolisis and catalityc pyrolisis were done by using batch reactor and the liquid product was analyzed by GC, GC$M S$ and FTIR. Product of pyrolisis process are olefines $C_{9}-C_{15}$ and product of catalytic process are olefines $C_{5}-C_{12}$.
\end{abstract}

Key words: acidic natural zeolite catalyst, pyrolisis, and catalytic pyrolisis

\section{PENDAHULUHAN}

Zeolit merupakan suatu kristalin aluminosilikat terhidrat dengan stuktur terbuka secara tiga dimensi yang dapat dipreparasi untuk meningkatkan aktivitasnya (Barthomeuf et.al., 1985). Zeolit memiliki fungsi sebagai katalis karena sifat-sifat pada permukaannya. Kation yang menetralkan muatan negatif dalam zeolit dapat dipertukarkan dengan kation lain dan dengan proses pemanasan akan terbentuk tapak asam bronsted. Tapak asam bronsted merupakan donor proton, dengan demikian akan dapat meningkatkan aktivitas katalis zeolit.

Zeolit juga mempunyai struktur mikroporous sehingga dapat menyediakan tempat yang besar untuk terjadinya reaksi serta memungkinkan reaksi dapat berlangsung pada tekanan yang lebih tinggi. Rasio $\mathrm{Si} / \mathrm{Al}$ yang cukup tinggi pada zeolit menyebabkan zeolit bersifat hidrofobik- 
organofilik yang akan mendukung proses difusi reaktan. Dimensi molekular zeolit juga menyebabkan zeolit selektif terhadap reaktan, produk, serta keadaan transisi (Hamdan, 1992).

Dari uji pendahuluan terhadap zeolit alam Wonosari dengan menggunakan difraksi sinar $\mathrm{x}$ diketahui bahwa sebagian besar penyusunnya adalah mordenit (Windarti, 2001). Menurut Haag and Chen (Hegedus, 1987) mordenit termasuk zeolit berpori besar yang tersusun dari cincin 12 anggota sehingga dapat mengadsorpsi molekul berantai lurus, cabang maupun siklik. Dyer (1988) menambahkan bahwa mordenit juga memiliki stabilitas termal yang tinggi, karena mampu mempertahankan strukturnya sampai temperatur $800-900^{\circ} \mathrm{C}$ dan memiliki stabilitas yang cukup tinggi terhadap asam.

Polietilena sebagai bahan dasar pembuatan kantong plastik merupakan polimer termoplastik sehingga dapat terdegradasi dengan adanya perlakuan termal (Gandinagar, 2000). Salah satu metode perlakuan termal yang bisa digunakan adalah pirolisis atau proses peruraian bahan organik secara termal tanpa oksigen, produk yang dihasilkan berupa cairan, gas, dan padatan (Agra, 1995). Pirolisis tidak melepaskan polutan berupa partikel dan $\mathrm{CO}_{2}$ ke atmosfer sehingga praktis tidak mengganggu lingkungan. Untuk tujuan tertentu pirolisis dapat dikombinasikan dengan proses katalitik reforming sehingga diperoleh produk dengan selektivitas yang tinggi.

Polimer jenis polietilena merupakan poliolefin yang bila dipirolisis akan menghasilkan hidrokarbon, suatu fraksi bahan bakar yang dengan proses lebih lanjut dapat diubah menjadi minyak tanah, bensin, dan bahan kimia lain. Panas menyebabkan molekul plastik terurai dan terbentuk potongan-potongan senyawa organik. Species yang terbentuk setelah degradasi dapat berupa monomer, dimer atau trimer, serta hidrogen, karbon monoksida, karbon dioksida, metana dan molekul hidrokarbon lain (Guddeti, et.al., 1979).

Menurut Gates et. al (1979), reaksinya adalah reaksi kraking di mana terjadi pemutusan ikatan C-C dan karena reaksi ini endotermik maka diperlukan temperatur tinggi. Secara umum untuk polietilena yang terjadi adalah:

$$
\mathrm{C}_{\mathrm{NH} 2 \mathrm{n}+2} \longrightarrow \begin{aligned}
& \mathrm{C}_{\mathrm{m}} \mathrm{H}_{2 \mathrm{~m}}+ \\
& \text { olefin }
\end{aligned} \begin{aligned}
& \mathrm{C}_{\mathrm{p}} \mathrm{H}_{2 \mathrm{p}+2} \\
& \text { parafin }
\end{aligned}
$$

di $\operatorname{mana} n=m+p$

Olefin yang dihasilkan dapat mengalami kraking kembali:

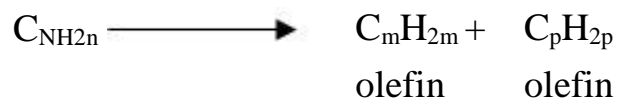

di mana $n=m+p$

Mekanisme reaksi pada pirolisis adalah melalui mekanisme radikal bebas. Dimulai dengan tahap inisiasi, homolisis ikatan karbon-karbon. Radikal yang terbentuk dapat mengalami pemutusan untuk menghasilkan etilen dan radikal primer yang telah kehilangan dua atom karbon. Pemutusan ikatan karbon-karbon terjadi pada posisi $\beta$ dari atom karbon dengan elektron tak berpasangan. Radikal bebas primer baru dapat kembali mengalami pemutusan $\beta$ dan unit radikal yang lebih kecil, sampai terbentuk metil radikal.

Radikal metil mengikat hidrogen dari molekul polietilena yang lain, menghasilkan radikal sekunder yang acak dan metana. Radikal dapat mengalami pemutusan $\beta$, menghasilkan $\alpha$-olefin dan radikal bebas primer. Reaksi yang pertama akan terulang kembali samapi terbentuk etilen dalan jumlah besar, metana dan $\alpha$-olefin.

Reaksi kraking yang dikatalisis oleh permukaan asam mengalami mekanisme intermediet ionkabonium. Pemutusan heteropolar ikatan $\mathrm{C}-\mathrm{H}$ dari molekul polietilena dapat membentuk baik ion karbonium maupun karbanion. Energi yang berhubungan dengan reaksi ini termasuk energi ionisasi dan afinitas elektron hidrogen dan gugus alkil dikaitan dengan energi disosiasi ikatan C- 
H. Energi yang dibutuhkan untuk pembentukan ion karbonium meningkat dengan meningkatnya jumlah atom $\mathrm{H}$ yang berikatan dengan atom $\mathrm{C}$ di mana ion hidrid berasal.

Transfer ion hidrid yang sama dapat terjadi selama interaksi antara ion-karbonium dengan hidrokarbon jenuh untuk membentuk ion karbonium yang baru. Reaksi penting dari ion karbonium adalah penataan ulang oleh atom hidrogen dan perubahan atom karbon. Bentuk tersebut membawa kepada isomerisasi ikatan rangkap dari suatu olefin (Gates, et.al., 1979).

Karena katalis yang digunakan untuk proses reforming memiliki beberapa persyaratan utama, seperti luas permukaan yang besar, volume pori yang besar, jari-jari yang homogen serta sifat kimia yang menunjang khususnya sifat keasamannya. Untuk itu diperlukan upaya untuk mendapatkan keempat hal tersebut dengan preparasi yang dilakukan. Luas permukaan dan volume pori yang besar serta jari-jari pori yang homogen akan membantu reaktan hasil pirolisis polietilena untuk melakukan reaksi dengan situssitus asam yang dimiliki oleh katalis sehingga aktivitas katalis untuk menghasilkan hidrokarbon akan meningkat.

\section{METODA PENELITIAN}

\section{a. Preparasi Bahan}

Pembuatan Katalis. Sampel zeolit alam Wonosari dicuci dengan akuades untuk menghilangkan pengotor yang larut dalam air dan dilanjutkan dengan pengeringan. Zeolit kering kemudian diayak dengan ayakan 100 mesh, selanjutnya dilakukan perendaman dalam larutan HF 1\% dengan rasio 1: $2(\mathrm{v} / \mathrm{v})$ selama 10 menit kemudian dicuci dengan akuades.

Selanjutnya dilakukan perendaman dalam larutan asam klorida $6 \mathrm{~N}$ dan direfluks selama 30 menit pada suhu $90{ }^{\circ} \mathrm{C}$, rendaman dibiarkan semalaman, baru kemudian dicuci dengan akuades sampai pHnya sama dengan 6 . Berikutnya zeolit dikeringkan dalam oven pada suhu $130{ }^{\circ} \mathrm{C}$ selama 1 jam untuk menghilangkan air dan dilanjutkan dengan perendaman dalam larutan $\mathrm{NH}_{4} \mathrm{Cl}$ 0,1 M dengan rasio 1: 2 (v/v) pada suhu $90{ }^{\circ} \mathrm{C}$ selama 3 jam per hari sampai satu minggu. Zeolit kembali dikeringkan dan dikalsinasi pada suhu $500{ }^{\circ} \mathrm{C}$ selama 4 jam dan dilanjutkan dengan kalsinasi dengan gas $\mathrm{N}_{2}$ selama 4 jam pada suhu $500{ }^{\circ} \mathrm{C}$. Zeolit siap untuk dikarakterisasi dan digunakan sebagai katalis.

Karakterisasi katalis meliputi rasio $\mathrm{Si} / \mathrm{Al}$, keasaman, luas permukaan, volume pori dan rerata jejari pori, masing-masing dilakukan dengan spektroskopi serapan atom, dengan metode adsorpsi basa dan dengan alat penganalisis luas permukaan merk NOVA Data Analysis Package ver 2.00 milik Pusat Penelitian Nuklir Yogyakarta.

Pemilihan plastik. Plastik dipilih yang benarbenar mengandung poliolefin. Pertama bahwa pemilihan berdasarkan uji termal, yaitu bila plastik ditusuk dengan besi panas dapat melunak berarti bersifat termoplastik, bila tetap keras berarti termoset. Berikutnya dilakukan uji perendaman, bila plastik mengapung dalam air, berarti mengandung poliolefin. Selanjutnya adalah uji pembakaran, bila saat dibakar ujungnya terjadi nyala biru dengan ujung nyala berwarna kuning berarti mengandung polietilena dan polipropilena, bila timbul bau seperti parafin dan terbakar dengan cepat berarti plastik tersebut adalah polietilena.

\section{b. Proses pirolisis}

Proses pirolisis katalitik terhadap plastik dilakukan dengan reaktor batch, katalis dan umpan diletakkan pada satu reaktor dan gas hasil reaksi katalitik dialirkan ke pendingin dengan bantuan gas $\mathrm{N}_{2}$. Katalis yang digunakan dalam bentuk pelet sebanyak 5 gram dan proses dilangsungkan pada temperatur $280{ }^{\circ} \mathrm{C}$ selama 45 menit. Untuk proses pirolisis tanpa katalis, dilakukan dengan mengosongkan tempat katalis dan proses dilangsungkan pada kondisi yang sama. Hasil pirolisis yang diperoleh pada 
kondensor kemudian dianalisis dengan kromatografi gas, GC-MS dan spektroskopi FTIR.

\section{HASIL DAN PEMBAHASAN}

\section{Pembuatan Katalis}

Hasil preparasi yang dilakukan terhadap zeolit alam Wonosari memberikan hasil sebagai berikut:

Tabel 1. Hasil karakterisasi keasaman zeolit alam Wonosari sebelum dan sesudah preparasi

\begin{tabular}{cc}
\hline Jenis Zeolit & Keasaman $(\mathrm{mmol} / \mathrm{g})$ \\
\hline$Z 1$ & 2,391 \\
Z2 & 5,56 \\
\hline
\end{tabular}

Keterangan:

$\mathrm{Z} 1$ = zeolit alam

$\mathrm{Z} 2$ = zeolit alam asam hasil preparasi

Tabel 2. Hasil karakterisasirasio $\mathrm{Si} / \mathrm{Al}$ zeolit alam Wonosari sebelum dan sesudah preparasi

\begin{tabular}{cc}
\hline Jenis Zeolit & Rasio Si/Al \\
\hline Z1 & 4,75 \\
Z2 & 11,73
\end{tabular}

Keterangan:

$\mathrm{Z} 1$ = zeolit alam

$\mathrm{Z2}=$ zeolit alam asam hasil preparasi

Keasaman yang diperoleh pada analisis ini adalah keasaman total dari katalis. Analisis keasaman dilakukan untuk mengetahui keasaman dari katalis yang telah dibuat dan metode yang digunakan adalah gravimetri yaitu mengukur banyaknya gas amonia yang dapat diadsorpsi oleh sampel. Pada prinsipnya gas amonia tersebut akan menempati situs-situs asam Lewis maupun asam Bronsted. Keasaman suatu katalis menurut Bronsted adalah kemampuan katalis untuk memberikan proton, sedangkan menurut Lewis, keasaman suatu katalis adalah kemampuan untuk menerima pasangan elektron dari molekul basa sehingga dapat terikat secara kimia pada permukaan katalis. Peningkatan keasaman sebesar 133\% ini diharapkan dapat meningkatkan aktivitas katalis.

Tabel 3. Hasil karakterisasi fisik zeolit alam Wonosari sebelum dan sesudah preparasi

\begin{tabular}{cccc}
\hline $\begin{array}{c}\text { Jenis } \\
\text { Zeolit }\end{array}$ & $\begin{array}{c}\text { Luas } \\
\text { Permukaan } \\
\left(\mathrm{m}^{2} / \mathrm{g}\right)\end{array}$ & $\begin{array}{c}\text { Volume } \\
\text { Pori }(\mathrm{cc} / \mathrm{g})\end{array}$ & $\begin{array}{c}\text { Rerata } \\
\text { Jejari } \\
\text { Pori } \\
(\AA)\end{array}$ \\
\hline $\mathrm{Z1}$ & 24,14 & $74,25.10^{-3}$ & 60,54 \\
$\mathrm{Z} 2$ & 204,64 & $147,02.10^{-3}$ & 14,37 \\
\hline
\end{tabular}

Keterangan:

$\mathrm{Z1}=$ zeolit alam

$\mathrm{Z} 2=$ zeolit alam asam hasil preparasi

Rasio Si/Al meningkat dari 4,75 menjadi 11,73. Peningkatan rasio $\mathrm{Si} / \mathrm{Al}$ ini sangat diharapkan, karena rasio $\mathrm{Si} / \mathrm{Al}$ yang tinggi akan meningkatkan stabilitas thermal zeolit. Peningkatan rasio Si/Al berarti meningkatkan jarak antara situs $\left[\mathrm{AlO}_{4}\right]^{-}$. Akibat dari keadaan ini adalah perlindungan elektrostatik kationkation bermuatan tinggi tidak berpengaruh sehingga pembentukan ion-ion akan bertambah dengan adanya hidrolisis. Peningkatan rasio Si/Al juga akan meningkatkan keasaman zeolit, karena pada umumnya sifat keasaman zeolit ditentukan oleh adanya gugus hidroksida yang terikat pada Aluminium atau pada situs SilikonAluminium.

Dealuminasi dan dekationisasi ini terjadi karena $\mathrm{HCl}$ bereaksi dengan alumina membentuk $\mathrm{AlCl}_{3}$ dan $\mathrm{MCl}_{\mathrm{n}}$. Perendaman zeolit hasil perlakuan asam kedalam larutan $\mathrm{NH}_{4} \mathrm{Cl} \quad 0,1 \quad \mathrm{~N}$ pada temperatur $90 \quad{ }^{\circ} \mathrm{C}$ selama 1 minggu, menyebabkan terjadinya penggantian kationkation yang ada dalam zeolit dengan ion $\mathrm{NH}_{4}{ }^{+}$, dan dengan kalsinasi pada temperatur $500{ }^{\circ} \mathrm{C}$ selama 4 jam dapat mengubah ion tersebut menjadi ion $\mathrm{H}^{+}$. Contoh reaksi yang terjadi dapat digambarkan sebagai berikut: 


$$
\begin{gathered}
\mathrm{NaZ}_{(\mathrm{S})}+\mathrm{NH}_{4}{ }^{+}{ }_{(\mathrm{aq})} \stackrel{\mathrm{NH}_{4} \mathrm{Z}_{(\mathrm{s})}+\mathrm{Na}^{+}{ }_{(\mathrm{aq})}}{\rightleftarrows} \\
\mathrm{NH}_{4} \mathrm{Z}_{(\mathrm{s})} \stackrel{\text { Kalsinasi }}{\longrightarrow} \mathrm{NH}_{3(\mathrm{~g})}+\mathrm{HZ}_{(\mathrm{s})}
\end{gathered}
$$

Analisis fisika menunjukkan telah terjadi peningkatan luas permukaan katalis sebesar $748 \%$ diikuti dengan peningkatan volume pori sebesar $98 \%$, dengan demikian akan mendukung reaksi katalitik karena akan semakin banyak reaktan yang dapat masuk kedalam pori. Semakin banyak reaktan yang dapat masuk kedalam pori berarti akan semakin besar peluang untuk terjadinya reaksi katalitik, atau dengan kata lain aktivitas katalis dalam mendukung terjadinya reaksi akan meningkat. Sedangkan turunnya rerata jejari pori sebesar $76 \%$ ini disebabkan oleh berkembangnya struktur pori oleh aktivasi yang dilakukan sehingga banyak muncul pori baru dengan ukuran yang seragam. Munculnya banyak pori baru dengan ukuran yang seragam akan menyebabkan terjadinya peningkatan luas permukaan.

\section{Proses pirolisis}

Proses pirolisis dilakukan dalam suatu reaktor bach yang dibuat dalam kondisi inert dengan mengalirkan gas $\mathrm{N}_{2}$ selama proses berlangsung. Gas produk pirolisis kemudian akan keluar melalui suatu pendingin spriral yang berada dalam suatu wadah yang berisis campuran es dan garam. Hasil kondensasi berupa cairan kemudian dianalisa dengan GC dan GC-MS serta FTIR. Pada proses pirolisis katalitik, ditempatkan katalis seberat 2 gram kedalam reaktor yang sama.

Spektra FTIR dari plastik sebelum dipirolis dan sesudah dipirolis baik dengan atau tanpa katalis menunjukkan perbedaan yang sangat nyata. Pada spektra plastik awal terlihat adanya serapan untuk ikatan $\mathrm{C}-\mathrm{H}$ pada panjang gelombang 2956,7 dan $1377 \mathrm{~cm}^{-1}$, yang menandakan adanya gugus $\mathrm{CH}_{3}$. Muncul pula serapan untuk ikatan C$\mathrm{H}$ pada panjang gelombang 2918,1 dan 1450,1 $\mathrm{cm}^{-1}$ yang menandakan adanya gugus $\mathrm{CH}_{2}$. Dengan demikian jelas bahwa sampel plastik yang digunakan benar-benar mengandung polietilena.

Setelah proses pirolisis baik dengan ataupun tanpa katalis, pada spektra muncul serapan baru pada panjang gelombang $3074,3 \mathrm{~cm}^{-1}$ yang menandakan adanya ikatan $=\mathrm{C}-\mathrm{H}$ dan serapan pada panjang gelombang $1649,0 \mathrm{~cm}^{-1}$ yang menandakan adanya ikatan $\mathrm{C}=\mathrm{C}$. Muncul pula serapan pada panjang gelombang $887,2 \mathrm{~cm}^{-1}$ yang menandakan adanya $\mathrm{C}=\mathrm{C}$ disubstitusi dan $839,0 \mathrm{~cm}^{-1}$ yang menandakan adanya $\mathrm{C}=\mathrm{C}$ trisubstitusi. Serapan pada 968,2 dan $738,7 \mathrm{~cm}^{-1}$ menandakan adanya masing-masing ikatan $\mathrm{C}=$ $\mathrm{C}$ trans dan $\mathrm{C}=\mathrm{C}$ cis. Hal tersebut mengindikasikan bahwa pirolisis menghasilkan produk dengan kandungan senyawa olefin.

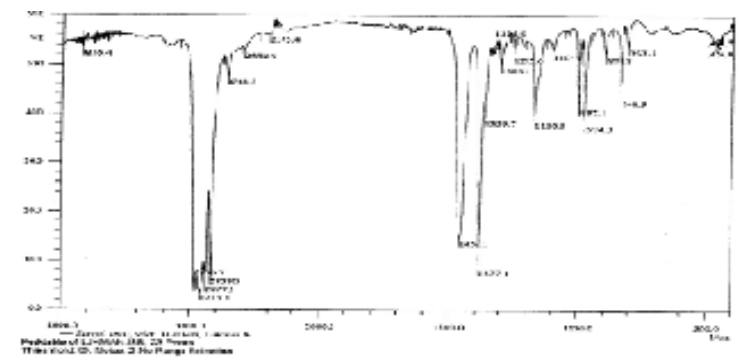

(a)

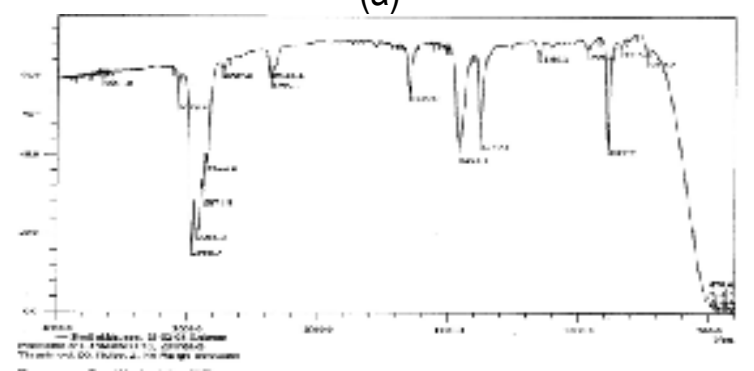

(b)

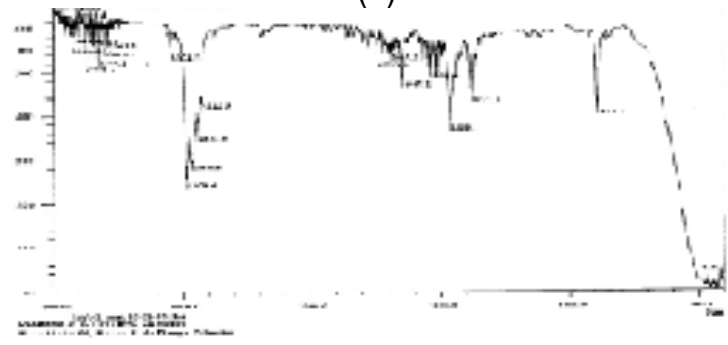

(c)

Gambar 1. a. Spektra FTIR plastik (b) Spektra FTIR pirolisis plastik tanpa katalis (c) Spektra FTIR pirolisis plastik dengan katalis zeolit alam asam 
Kromatogram GC menunjukkan bahwa pada pirolisis katalitik dihasilkan produk dengan berat molekul yang lebih rendah dari pada produk yang dihasilkan pada proses pirolisis tanpa katalis. Menurut Campbell (1988) situs asam pada zeolit tergolong memiliki keasaman tinggi dan dapat menarik muatan positif yang diabsorpsi secara kimia dari alkana, atau dalam hal ini polietilena. Proses tersebut memungkinkan keterlibatan transfer hidrida dari situs Lewis, sedangkan pada situs Bronsted terjadi proses perengkahan dengan melalui intermediet karbonium.

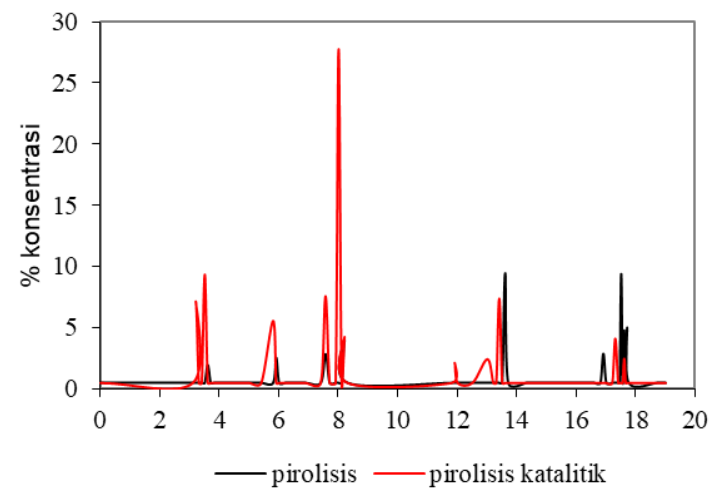

Gambar 2. Kromatogram hasil pirolisis piletilena

Peningkatan luas permukaan dan volume pori katalis juga mendukung peningkatan aktivitas katalis. Hal ini disebabkan karena lebih besarnya kemungkinan reaktan untuk masuk ke dalam pori katalis. Semakin besarnya peluang reaktan untuk masuk ke dalam pori berarti semakin besar pula peluang terjadinya reaksi katalitik antara reaktan dengan permukaan katalis

Dari analisis dengan menggunakan GC-MS diketahui bahwa produk pirolisis tanpa katalis adalah hidrokarbon $\mathrm{C}_{9}-\mathrm{C}_{15}$ sedangkan produk pirolisis dengan katalis adalah hidrokarbon $\mathrm{C}_{5}$ $\mathrm{C}_{12}$. Dengan demikian proses pirolisis dengan menggunakan katalis zeolit alam asam dapat meningkatkan produk hidrokarbon yang dihasilkan.

\section{KESIMPULAN}

Kesimpulan dari penelitian ini adalah preparasi terhadap zeolit alam Wonosari telah meningkatkan keasaman zeolit sebesar 132,5\%, rasio $\mathrm{Si} / \mathrm{Al}$ sebesar $146,9 \%$, luas permukaan sebesar $748 \%$, volume pori sebesar $98 \%$ dan menurunkan rerata jejari pori sebesar $76 \%$. Proses pirolisis polietilena tanpa katalis menghasilkan hidrokarbon $\mathrm{C}_{9}-\mathrm{C}_{15}$ sedangkan produk pirolisis polietilena dengan katalis zeolit alam asam menghasilkan hidrokarbon $\mathrm{C}_{5}-\mathrm{C}_{12}$.

\section{DAFTAR PUSTAKA}

Barthomeuf, D., dalam Imelik, B., Naccache, C., Coudurier, G., taarit, Y. B., and Vedrine, J. C., 1985, catalysis by acids and bases, elsevier, Amsterdam

Hamdan, H., 1992, Introduction to zeolites synthesis, characterization and modification, Universiti Teknologi Malaysia, Malaysia.

Windarti, T., 2001, Pengaruh kandungan logam kromium dan temperatur terhadap keefektivan katalis kromium-zeolit alam dalam proses perengkahan biofuel, Tesis, Program Pascasarjana UGM, Yogyakarta.

Haag, W. O. dan Chen, N. Y., dalam Hegedus, L. L., 1987, Catalyst Design, Progress and Perspectives, John Wiley and Sons, New York.

Dyer, A., 1988, An Introduction to Zeolite Molecular Sieves, John Wiley and Sons, New York.

Gandinagar, 2000, Plasma depolymerization of plastic, www.plasmaindia.com, Centre for Plasma Technologies, India.

Agra, S. W., 1995, Pirolisis getah beberapa jenis tanaman untuk membuat bahan bakar cair pengganti bahan bakar minyak bumi, Disertasi, UGM, Yogyakarta.

Guddeti, R. R., Knigh, R., and Grossmann, E. D., 2000, Plasma Chem. Plasma Processing 20, www.plasmaindia.com, Centre for Plasma Technologies, India.

Gates, B. C., Katzer, J. R. and Schuit, G. C., 1979, Chemistry of catalytic processes, McGraw-Hill, New York.

Campbell, I. M., 1988, Catalysis at surfaces, Chapman and Hall, London. 